ISSN: 2578-0379

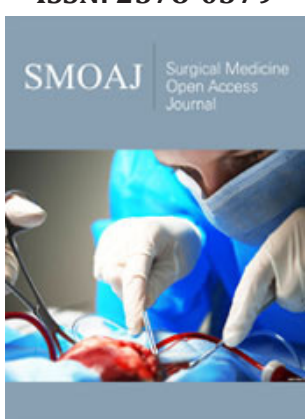

*Corresponding author: Morazán AD, Third-year Resident of General Surgery Residency, Honduras

Submission: 想 May 01, 2020

Published: 喟July 13, 2020

Volume 3 - Issue 4

How to cite this article: Morazán $A D$, Cortes C, Navas F, Bendeña C. Intestinal Intussusception in an Adult Affected by Vanek Tumor: A Case Report. Surg Med Open Acc J.3(4). SMOAJ.000567.2020. DOI: 10.31031/SMOAJ.2020.03.000567

Copyright@ Morazán AD, This article is distributed under the terms of the Creative Commons Attribution 4.0 International License, which permits unrestricted use and redistribution provided that the original author and source are credited.

\section{Intestinal Intussusception in an Adult Affected by Vanek Tumor: A Case Report}

\author{
Morazán $\mathrm{AD}^{1 *}$, Cortes $\mathrm{C}^{2}$, Navas $\mathrm{F}^{2}$ and Bendeña $\mathrm{C}^{3}$ \\ ${ }^{1}$ Third-year Resident of General Surgery Residency, Honduras \\ ${ }^{2}$ Specialist in General Surgery, Honduras \\ ${ }^{3}$ Specialist in Pathology, Honduras
}

\begin{abstract}
Inflammatory fibroid polyp (IFP) is a rare benign lesion, originating from the submucosa in the gastrointestinal tract. It generally appears as an isolated benign lesion, rarely located at the level of the ileum. Its origin is controversial. Clinical presentation varies depending on its location; invagination and obstruction are the most common indicative symptoms when the polyp is located at the level of the small intestine. We report the case of a 60-year old patient with abdominal pain, nausea and vomiting and a personal history of intermittent constipation. Radiological imaging objectified ileo-ileal invagination completely obstructing the ileum light. Segmental resection of the obstructed ileal segment and terminalterminal anastomosis were performed. The final diagnosis of IFP was established using histological examination.
\end{abstract}

Keywords: Inflammatory fibroid polyp; Ileum; Invagination

\section{Introduction}

Adult intussusception is relatively rare, constituting only $1 \%$ of patients with bowel obstructions. Adult intussusception is mostly caused by tumors and $80 \%$ of the tumors associated with small bowel intussusception are benign. Vanek tumor (inflammatory fibroid polyp) is a rare pseudo-tumorous lesion of the gastrointestinal tract first described by Vanek in 1949 [1]. It occurs most frequently in the gastric antrum of adults, inflammatory fibroid polyp (IFP) rarely cause ileal intussusception [2]. The IFP is a benign lesion that arises from the submucosa of the gastrointestinal (GI) tract, most commonly in the antrum (70\%) and ileum $(20 \%)$ and, only occasionally, in the duodenum and jejunum. Its frequency from $1 \%$ to $4 \%$ of diagnoses among benign lesions, and usually occurs between the fifth and the seventh decade of life [3]. The underlying cause of IFPs is still unknown. Many have suggested etiologies possibly related to chemical, physical, or metabolic triggers. Genetic study of IFP showed mutations in platelet derived growth factor alpha (PDGFRA) in some cases. The frequency of mutations among case series ranges from $21.7 \%$ to $69.6 \%$. Activating PDGFRA mutations occur in exons 12,14 and 18. It also shows for the presence of androgen receptorpositive cells whose location corresponds with the distribution of Ki67- positive cells. When localized in the small bowel, the presenting symptoms are colicky abdominal pain and obstruction. Intussusception due to IFPs is uncommon; moreover, jejunojejunal and ileoileal intussusception has only rarely been reported [4-14]. We present the case of a 60 -year-old male presenting with symptoms preceding an intestinal obstruction caused by an ileoileal intussusception with an inflammatory fibroid polyp acting as the lead point.

\section{Clinical Case}

A 60-year-old male patient, married, farmer, from Tegucigalpa, with a history of a month and a half of evolution, insidiously presenting moderately intense abdominal cramps, diffuse location with predominance in the right iliac fossa and mesogastrium, short duration, accompanied by nausea, vomiting twice a week, which is attenuated after the intake of 
analgesics and antispasmodics. Evaluated by general practitioner and managed with antispasmodics, changes in lifestyle and diet. The patient continued with insidious, sporadic, and self-limited episodes of pain until one day prior to admission presented an exacerbation with increased intensity without attenuating the intake of analgesics and antispasmodics, so he went to the emergency surgery assessment general. Pathological personal history of systemic arterial hypertension managed with irbersartan $300 \mathrm{mg}$ orally every day, benign prostatic hyperplasia treated with alfuzosin once daily, grade I obesity. On physical examination, the patient presented complaining with pain facies, hemodynamically stable with vital signs of BP 130/90mmhg, FC 96x, FR 16x, temperature of $36.5{ }^{\circ} \mathrm{C}$ without data of respiratory distress, oxygen saturation of $98 \%$ with ambient air , chest with well-ventilated lung fields with vesicular murmur, globular abdomen at the expense of adipose tissue, hypoactive intestinal noises 2 per minute, without distension, percussion without alterations, soft, depressible, moderate pain on deep palpation in the iliac fossa and right flank, no involuntary muscular resistance, no data of peritoneal irritation, no palpable tumors or visceromegalies. Genitals and inguinal region without alterations. No stool to the rectal touch. Laboratory tests were requested with the following results: $\mathrm{Hb} 12.1 \mathrm{~g} / \mathrm{dL}, \mathrm{H}$ to $38.5 \mathrm{~mL} / \mathrm{dL}$, VCM $91.9 \mu \mathrm{m}^{3}$, WBC. $10,800 / \mathrm{mm}^{3}$, neutrophils $72.2 \%$, platelets $474,000 / \mathrm{mm}^{3}$; Biochemical: Glucose $100 \mathrm{mg} / \mathrm{dL}, \mathrm{Na}$ $140 \mathrm{mEq} / \mathrm{L}, \mathrm{K} 4.4 \mathrm{mEq} / \mathrm{L}$, creatinine $1.0 \mathrm{mg} / \mathrm{dL}$, BUN $13.8 \mathrm{mg} / \mathrm{dL}$, urea $32.5 \mathrm{mg} / \mathrm{dL}$, Alb 5.1g/dL, TGO 23U/L, TGP 36U/L.

Subsequently, his study was complemented by requesting abdominal tomography. In which a proximal ileal loop was observed with the presence of distal cystic tumor that measures approximately $3.5 \mathrm{~cm}$ with proximal dilation of this intestinal loop with a hydro-air level, related to intestinal invagination. No data of intestinal obstruction, free fluid, or pneumoperitoneum were observed (Figure 1). He was admitted for surgical treatment with a diagnosis of intestinal invagination. A diagnostic laparoscopy was performed and turned in open laparotomy with the following findings, a firm consistency tumor in the small intestine at the level of the ileum $7 \mathrm{~cm}$ long and $3.5 \mathrm{~cm}$ in diameter, occupying the entire lumen of the intestine, with an ileo-ileal invagination segment of approximately $15 \mathrm{~cm}$ (Figure 2). The tumor was evaluated small intestine segment which measures $7 \mathrm{~cm}$ long by $3.5 \mathrm{~cm}$ in diameter with a light brown, smooth, shiny serosa, wall $4 \mathrm{~cm}$ thick, trabeculated mucosa preserved in the intestinal wall, a nodular mass measuring 4 by $3.5 \mathrm{~cm}$, gray, cream attached directly to the wall, clean surgical edges of soft consistency and gelatinous appearance, well defined, not encapsulated with moderate amount of non-foul, non-hot inflammatory fluid (Figure 3). It was decided to perform resection and ileo-ileum anastomosis, the patient evolved satisfactorily and began diet 24 hours post-operative and discharged 4 days later without complications. Histological reported myxoid-like lesion made up of elongated fibroblasts, also with an inflammatory infiltrate polyp accompanied by eosinophils. It grows in the submucosa, pushes and ulcerates the submucosa, with an acute inflammatory reaction. well-defined tumor without cell atypia or mitosis, normal surgical edges (Figure 4).
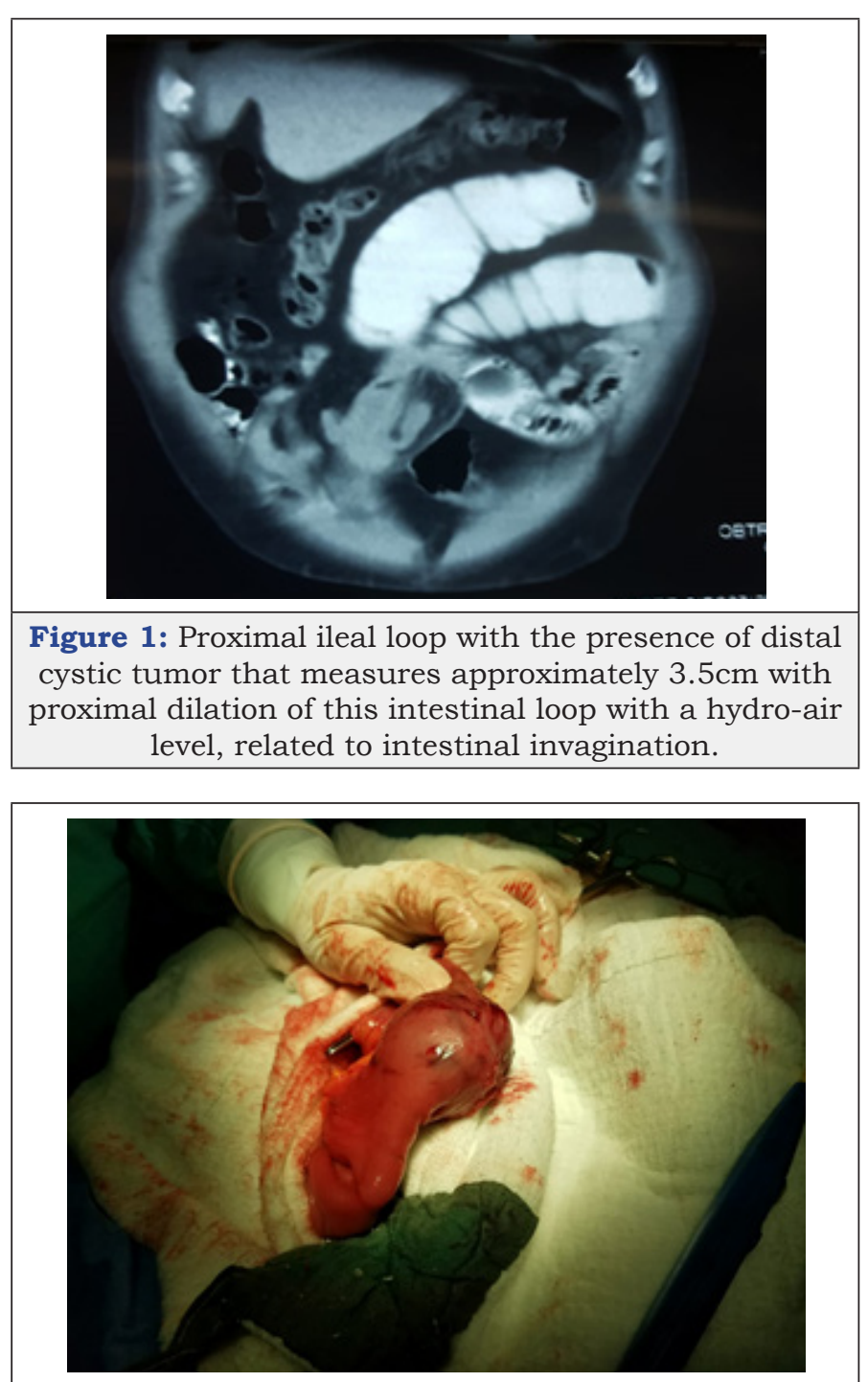

Figure 2: Firm consistency tumor in the ileum $7 \mathrm{~cm}$

long and $3.5 \mathrm{~cm}$ in diameter, occupying the entire lumen of the intestine, with an ileo-ileal invagination.

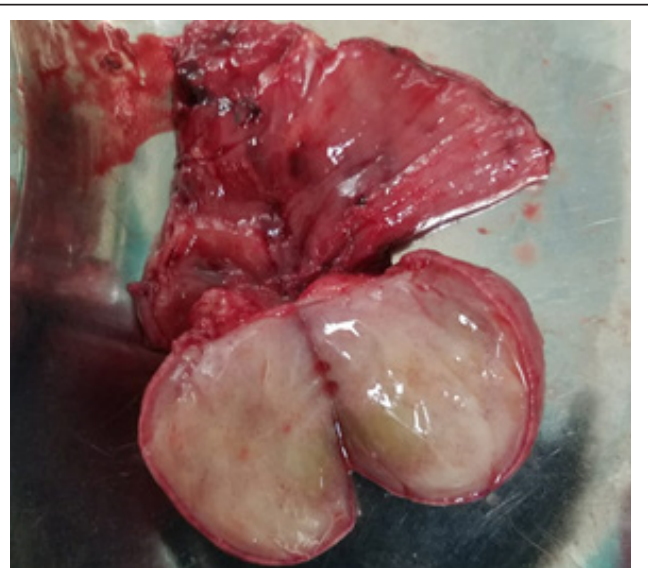

Figure 3: The tumor with a light brown, smooth, shiny serosa, trabeculated mucosa preserved in the intestinal wall, a nodular mass, cream attached directly to the

wall, clean surgical edges of soft consistency and gelatinous appearance, well defined, not encapsulated. 


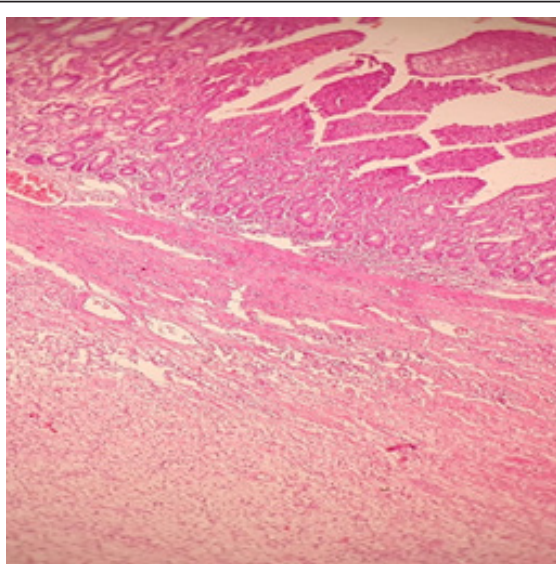

Figure 4: Histological reported myxoid-like lesion made up of elongated fibroblasts, also with an inflammatory infiltrate polyp accompanied by eosinophils.

\section{Discussion}

Inflammatory fibroid polyp (IFP) is a rare, benign lesion originating from the submucosa of the gastrointestinal tract [5]. The Inflammatory fibroid polyp (IFP) is a mesenchymal polypoid lesion of the gastrointestinal tract that follows a benign course. Incidence is extremely low: from $0.1 \%$ to $2 \%$ [6]. This tumor is discovered at any age but is more often in adults especially between 60 and 70 years old [7]. IFP was first described as "polypoid fibroma" in 1920 by Konjetzny. In 1949, Vanek named it as "gastric submucosal granuloma with eosinophilic infiltration" and described six cases. Later, it became recognized by a variety of different names: eosinophilic granuloma, polypoid fibroma, gastric fibroma with eosinophilic infiltration, polypoid eosinophilic granuloma, inflammatory pseudotumor, and Vanek's polyp. In 1953, Helwig et al. introduced the term "inflammatory fibroid polyp" to define the disease.

IFP lesion that arises from the GI tract submucosa, are classified as submucosal tumor of connective tissue; it is most commonly found in the antrum (70\%) and ileum (20\%). Other sites in descending order are colon, jejunum, duodenum, and esophagus. Rarely it reaches more than $6 \mathrm{~cm}$, however there is a case of IFP reported with $12.5 \mathrm{~cm}$ diameter [3]. Most of the studies correspond to cases reports. Probably one of the biggest reports is a review of 76 cases Johnstone and Morson found a relative incidence of $75 \%$ gastric, $18 \%$ small intestinal, $7 \%$ colonic, and $1 \%$ esophageal. IFP affects all ages, with the peak incidence in the fifth and sixth decades. In two reviews of IFPs a slight male predominance was found [4]. A case was reported in Costa Rica by Madriz et al. [9], in a 58 years old male, with history of three months of episodic abdominal pain. In laparotomy the finding was a jejunal tumor $(2 \mathrm{~cm})$, associated with intestinal invagination. The lesion was resected, and an ileo-jejunal anastomosis was performed. Histological report corresponds to IFP [8].

When symptomatic, Vanek's tumors are usually associated with abdominal pain, weight loss, bleeding, dyspeptic symptoms, iron deficiency anaemia and intussusception. Their size determines whether they are symptomatic or not. Clinical symptoms may vary according to the site and size of the tumor [9]. The most common acute sensation of an IFP in the small bowel is intussusception with bowel obstruction [5]. The diagnosis in adults is often more difficult because symptoms are usually non-specific and sometimes chronic with recurrent episodes of sub-acute obstruction. It is an unusual diagnosis in adults, accounting for only $5 \%$ of mechanical intestinal obstruction [10].

Abdominal tomography scanning is the most useful study because it reveals a mass with a central dense area and a halo of low attenuation representing the intussusceptum. Newer techniques which have recently assisted in the diagnosis include capsule endoscopy and retrograde double balloon enteroscopy [11]. Computed tomography widely indicated in adults, it makes it possible to make a positive diagnosis of intussusception and to describe, as far as possible, the causal lesion (site, spontaneous density). In our case, a proximal ileal loop was observed with the presence of distal cystic tumor that measures approximately $3.5 \mathrm{~cm}$ with proximal dilation of this intestinal loop with a hydro-air level, related to intestinal invagination. The search for signs of severity is essential for management and prognosis. The CT scan is the best test to predict intestinal distress [7].

The operation should be performed as early as possible in order to prevent the intussusceptions from leading to ischemia, necrosis and subsequent perforation of the invaginated bowel segment. Exploratory laparoscopy or laparotomy is frequently recommended as the best treatment for intussusceptions caused by IFP. When surgery is delayed and intestinal perforation with peritonitis occurs, there is a considerable increase in morbidity and mortality [13]. The appropriate management of adult intussusceptions remains controversial, with the debate focusing mostly on the issue of primary en bloc resection vs initial reduction followed by more limited resection. The vast majority of these lesions arise as a primary lesion, in which resection without reduction is recommended [14]. In our case, it was decided to perform resection and ileo-ileum anastomosis, the patient evolved satisfactorily.

\section{References}

1. Daum O, Hes O, Vanecek T, Benes Z, Sima R, et al. (2005) Vanek's Tumor (Inflammatory Fibroid Polyp). Report of 18 cases and comparison with three cases of original Vanek's series. Annals of Diagnostic Pathology $7(6): 337-347$.

2. Akbulut S, Mahsuni M, Cakabay Bahri, Sule Bakir, Ayhan Senol (2009) Giant inflammatory fibroid polyp of ileum causing intussusception: a case report. Cases J 2: 8616.

3. Fazzio C, Madeira E (2015) Inflammatory fibroid polyp (Vanek's polyp): a case report and literature review. J Bras Patol Med Lab 51(2): 117-120.

4. Bays D, Anagnostopoulos G, Katsaounos E, Filis P, Missas (2004) Inflammatory fibroid polyp of the small intestine causing intussusception: A report of two cases. Dig Dis Sci 49(10): 1677-1680.

5. Jukic Z, Ferencic Z, Radulovic P, Mijic A (2014) Estrogen and androgen receptors in inflammatory fibroid polyp (Vanek's Tumor): Case report. Anticancer Res 34(12): 7203-7206.

6. Lee C, Yuen MK (2014) Inflammatory fibroid polyps causing intussusception in adult patients: Two case reports and review of literature focusing on radiological features. Hong Kong J Radiol 17: 271276. 
7. Rossi P, Montuori M, Balassone V, Ricciardi E, Anemona L, et al. (2012) Inflammatory fibroid polyp. A case report and review of the literature. Ann Ital Chir 83(4): 347-351.

8. Ahtil R, Bensghir M, Meziane M, Houba A, Jaafari A, et al. (2017) Rare etiology of subocclusive syndrome: inflammatory fibroid polyp of the ileum, about a clinical case. Pan Afr Med J 26: 146.

9. Madriz DeHaan P, Martínez Y, Gutiérrez F (2014) Intestinal intussusception due to an inflammatory fibroid polyp (Vanek's tumor). Legal Medicine of Costa Rica-Virtual Edition 31(1): 1409-1415.

10. Paikos D, Moschos J, Tzilves D, Koulaouzidis A, Kouklakis G, et al. (2007) Inflammatory fibroid polyp or Vanek's tumour. Dig Surg 24: 231-233.
11. Yakan S, Calıskan C, Makay O, Denecli AG, Korkut MA (2009) Intussusception in adults: Clinical characteristics, diagnosis and operative strategies. World J Gastroenterol 15(16): 1985-1989.

12. Gara N, Falzarano J, Limm W, Namiki T (2009) Ileal inflammatory fibroid polyp causing chronic ileocolic intussusception and mimicking cecal carcinoma. World J Gastrointest Oncol 1(1): 89-92.

13. Bassam Abboud (2015) Vanek's tumor of the small bowel in adults. World J Gastroenterol 21(16): 4802-4808.

14. Zakaria A, Daradkeh S (2012) Jejunojejunal intussusception induced by a gastrointestinal stromal tumor. Case Rep Surg 2012: 173-680. 